\title{
Design of a mindfulness-based intervention to support teachers' emotional regulation behaviors
}

\author{
Douglas P. Kennedy ${ }^{1}$ (D) Alex Haley ${ }^{1} \cdot$ Roni Evans $^{1}$
}

Accepted: 31 December 2021

(c) The Author(s) 2022

\begin{abstract}
Addressing teachers' ability to better navigate stress and emotional responses has the potential to improve classroom behaviors, student learning as well as teachers' wellbeing. While there is growing interest in mindfulness-based interventions (MBIs), there is need for greater attention to design aligned with relevant theories and transparent reporting to improve the rigor and translation of research. While utilized widely in health and behavior fields, behavior change theory has not been applied extensively in education or MBI research. This descriptive methodological paper articulates the intervention mapping and design process of an MBI to improve teachers' stress and emotional regulation. To improve reporting, we use a post hoc application of a well-established behavioral model. Application of the Behavior Change Wheel (BCW) as part of an intervention mapping approach for an MBI to align teacher's needs with intervention elements most likely to achieve desired behavioral outcomes. The paper illustrates an approach which includes defining the problem in behavioral terms, identification of target behaviors and behavioral change techniques, and selection of strategies and modes of intervention delivery. A systematic intervention mapping approach applying the BCW can yield a holistic MBI for the desired behavior change, enhanced emotion and stress regulation in teachers. This example of applying the BCW to the design of an MBI demonstrates how intervention designers and researchers can make decisions about which techniques and delivery components to include in their interventions, and how to systematically describe them. Such approaches have the potential to improve the reporting and methodological rigor of future MBI research and the successful application of interventions in practice.
\end{abstract}

Keywords Mindfulness $\cdot$ Intervention design $\cdot$ Behavior change $\cdot$ Emotional regulation $\cdot$ Stress $\cdot$ Education

\section{Background}

Stress among teachers is a growing problem which negatively affects their own health, as well as student learning. Globally, $20-26 \%$ of teachers experience high degrees of stress at work (Dawn et al., 2016; Garrick et al., 2014; Hecker et al., 2018; Kyriacou, 2001; Liu \& Onwuegbuzie, 2012; Travers, 2017; Zurlo et al., 2013), with rates similar to those experienced by doctors and nurses (Gallup, 2014;

Douglas P. Kennedy

dougk@umn.edu

Alex Haley

haley045@umn.edu

Roni Evans

evans972@umn.edu

1 University of Minnesota, Earl E. Bakken Center for Spirituality \& Healing, 420 Delaware Street S.E., Minneapolis, MN 55455, USA
Johnson et al., 2005). Currently, teachers find themselves adapting to rapidly changing instructional environments and uncertainties. These new challenges add to the many contributors to teacher stress including limited financial resources, growing class sizes, diminished autonomy, highstakes testing (Gallup, 2014; Kena et al., 2015; McCarthy et al., 2017) and threats of physical violence (Espelage et al., 2013). Further, teachers often lack the training to manage stress and promote emotional wellbeing for themselves and others (Greenberg et al., 2016). Given these circumstances, it is little surprise that a staggering number of educators, especially newer teachers and those in high-poverty, urban and rural schools, are leaving the profession at a rapid rate (Haynes et al., 2014; Ingersol et al., 2018; MetLife, 2012). Importantly, teacher stress affects more than attrition and educator health and wellbeing. When teachers are stressed it can impact how they teach and their ability to meet students' needs. This limits their capacity to implement effective teaching strategies (Larson et al., 2018) as well as the 
ability to form effective teacher-student relationships which can negatively influence student engagement and learning (Quin, 2017; Gallup, 2014).

There has been growing interest in mindfulness and mindfulness-based interventions (MBIs) to help teachers respond more effectively to work-related stress and improve learning environments (Flook et al., 2013; Harris et al., 2016; Hwang et al., 2017; Klingbeil et al., 2017; Klingbeil \& Renshaw, 2018; Roeser et al., 2012; Schussler et al., 2018; Soloway, 2016; Zarate et al., 2019). Systematic reviews and meta-analyses have found MBIs to be promising for relieving stress, anxiety, and depression in the general population (Gotink et al., 2015; Goyal et al., 2014; Khoury et al., 2015; Lomas et al., 2019). Similarly, recent research of MBIs for teachers suggests these approaches may have a positive effect on teacher emotional regulation which may aid teachers work with students, help moderate stress and anxiety, decrease attrition and improve teacher self-efficacy and resilience (Emerson et al., 2017; Hwang et al., 2017; Klingbeil \& Renshaw, 2018; Lomas et al., 2017; Zarate et al., 2019).

Mindfulness can be defined as attentional self-regulation focused on the present moment, and an "orientation towards one's experience in the present moment...characterized by curiosity, openness, and acceptance" (Bishop et al., 2004, p. 232). Through practice, individuals can develop the ability to step back from a situation and observe their thoughts and emotions while still participating in the situation (Creswell, 2017; Lomas et al., 2019). By cultivating this participantobserver capacity, they can then choose adaptive behavioral responses to emotional events (e.g., pausing and perspective taking before reacting, and exercising self-care) (Lomas et al., 2019). Through the application of mindfulness, maladaptive behavioral responses associated with stress can be ameliorated (e.g., absenteeism, substance use, disengagement, and increased emotional reactivity) (Herman et al., 2018; Jennings \& Greenberg, 2009; Montgomery \& Rupp, 2005). MBIs are multi-element programs that focus on the development of mindfulness skills to facilitate emotional regulation behaviors necessary for effectively managing stress and anxiety (Crane et al., 2017; Klingbeil \& Renshaw, 2018). Essential content of MBIs include regulating attention and emotions, establishing body awareness, and shifting self-perceptions. Curricula often include interactive inquiry, experiential learning, meditation practices, and mindful movement to develop mindfulness skills (Crane et al., 2017). Delivery approaches for MBIs vary greatly in terms of structure (i.e., number and length of sessions, frequency, group, etc.) and delivery format and support materials (i.e., in-person, online, app, etc.) (Crane et al., 2017; Creswell, 2017). Indeed, with the growing interest in mindfulness and a rapid proliferation of new MBI program forms, there have been growing concerns about integrity and fidelity which are crucial for driving the mindfulness field forward (Crane \& Hecht, 2018). While the research of MBIs is promising, the methodological quality of the studies to date still varies considerably with incomplete intervention reporting of the complex, multi-element nature of MBIs. This makes results interpretation difficult and severely limits successful replication in other settings. (Emerson et al., 2017; Hwang et al., 2017).

Developing robust MBIs to address current gaps and concerns could be remedied by applying more systematic and intentional processes to their design and development. Intervention mapping is a multistep process that has been advocated in other fields for improving the design of complex interventions to enhance fidelity and dissemination (Craig et al., 2013; Crane \& Hecht, 2018; Hurley et al., 2015; Kok, 2018). Essential features include needs assessment, problem and outcome identification, selection of appropriate methods and applications, development of the intervention or program plan, implementation, and finally development of an evaluation plan (Hurley et al., 2015).

Since MBIs address teachers' emotional regulatory behaviors, one way to apply intervention mapping to MBI design for emotional regulation behaviors in educational settings is to apply the Behaviour Change Wheel (BCW) (Michie et al., 2014). The BCW utilizes a behavior change theory approach which focuses on the physical and psychological capabilities needed for new behaviors, the social and physical opportunities to develop the behaviors, and the necessary motivations to behavior engagement (Michie et al., 2014). The BCW has the advantage of being a coherent, theory-driven, systematic design approach which can facilitate intervention mapping. The Theoretical Domains Framework (TDF) is an integrated framework associated with the $\mathrm{BCW}$ and can be used to match stakeholder capability, opportunity, and motivational related needs to specific intervention elements (Cane et al., 2012: Michie et al., 2014). While the BCW is gaining widespread use in the health and behavioral fields to address smoking cessation (Minian et al., 2020) infectious disease transmission (Bonell et al., 2020; Michie et al., 2020), and physical activity promotion (Eisele et al., 2020), we are unaware of its application to interventions addressing educators' emotional regulation through mindfulness.

The purpose of this paper is to describe the intervention mapping process of an MBI. This descriptive, methodological article will provide an example for the transparent reporting and mapping of MBI interventions, with the aim of improving the methodological quality of MBIs in the education field over the long term.

\section{Methods}

This work was classified as 'not human subjects research' by the University of Minnesota Internal Review Board. The preparation of the MBI described in this paper was 
in anticipation of a larger demonstration project. In this paper, we use the $\mathrm{BCW}$ to organize the reporting of our intervention mapping process to demonstrate the more detailed alignments of the MBI intervention elements to teacher needs and desired behavioral outcomes (Michie et al., 2014). An overview of the process is illustrated in Fig. 1.

The BCW steps include identifying and defining the behavior and then what needs to change, selecting intervention functions to bring about the desired change, and then determining how the intervention will be delivered (Michie et al., 2014, p. 59). The sixth step (related to policy changes) is not addressed as it was beyond the scope of the demonstration project.

Steps 1-3 of the BCW approach requires defining the problem in behavioral terms and selecting and specifying the target behavior. This step includes reviewing the research literature to identify the key problem, problem behaviors, and individuals required to engage in the behaviors. As part of our MBI development, we reviewed existing literature on mindfulness in education, teacher stress and professional development. We also sought feedback from other researchers and educators through surveys and interviews $(n=93)$. This information was used to narrow the focus to target behaviors most likely to have an impact on desired outcomes and other behaviors, as well as those that were likely to change, and feasible to measure. Once the target behavior was determined, we were able to focus on what the intended population needed to do to accomplish the change, frequency and timing, location of the behavior change, and with whom the target population would do the targeted behavior.

Step 4 of the BCW entails identifying what needs to change for the desired behaviors to occur. We used information from the literature and from educators in the field to identify what teachers needed to engage in the target behavior. This illustrated the target population's needs, which can be described broadly in behavioral terms of capabilities, opportunities, and motivations (COM) which are essential elements of the BCW. According to Michie, if behavior change is to occur, the individual or group must have the capabilities to do the behavior, opportunities to perform the behavior in a supportive environment, and motivation to enact the behavior (Michie et al., 2014, p. 59).

Teachers' capability, opportunity and motivational needs can be described using the TDF) (Cane et al., 2012: Michie et al., 2014). The TDF consists of 14 domains that are extensions of the BCW. The TDF domains are: 1) physical skills, 2) knowledge, 3) memory, attention, and decision processes, 4) behavioral regulation, 5) environmental context and resources, 6) social influences, 7) reinforcement, 8) emotion, 9) professional/social role and identity, 10) beliefs about capabilities, 11) optimism, 12) beliefs about consequences, 13) intentions, and 14) goals (Cane et al., 2012).

Steps 5-8 of the BCW involves identifying appropriate intervention functions and behavior change techniques, as well as modes of delivery. The BCW requires considering which modes of delivery are most appropriate for the given circumstances taking into account factors that could affect implementation and sustainability. In the BCW model,

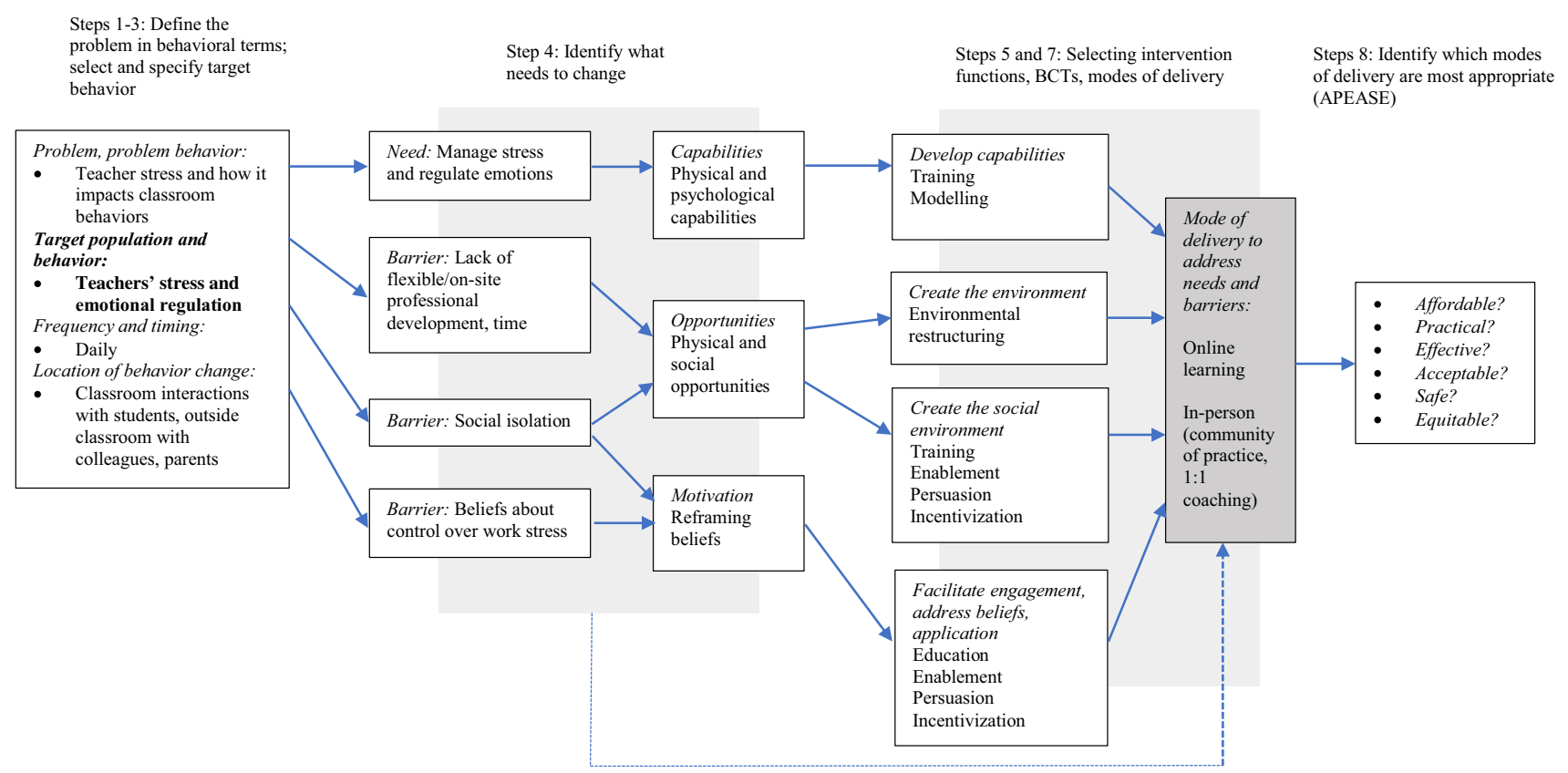

Fig. 1 Mindfulness in Education Intervention Design Process using Michie, Atkin, \& West's (2014) Behavior Change Wheel 
these criteria include affordability, practicality, effectiveness, acceptability, safety, and equity (Michie et al., 2014). We can combine the information from Step 1 with the COM elements and TDF components identified in Step 4 to select intervention functions best suited to bring about our intended behavior change. Intervention functions, in the $\mathrm{BCW}$, are the "broad categories of means by which an intervention can change behavior" (Michie et al., 2014, p. 109). Under each broad category, specific behavior change techniques (BCTs) are selected. BCTs are the active components that bring about a change in behavior (Michie et al., 2014, p. 145). The behavioral targets, population and needs identified in Steps 1-4, combined with the intervention functions and BCTs in steps 5-7, determines the intervention's mode of delivery (step 8 ) or how the intervention content is to be implemented.

\section{Results}

Figure 1 illustrates the overall results of the intervention mapping approach with the details of each of intervention mapping steps described according to the $\mathrm{BCW}$ format.

Step 1-3 Based on the literature and feedback provided by researchers and educators, we identified teacher work-related stress as a core problem to be addressed (Dawn et al., 2016; Garrick et al., 2014; Hecker et al., 2018; Travers, 2017). The inability of teachers to effectively navigate stressors results in their own emotional reactivity and rumination behaviors (Skinner \& Beers, 2016). This can lead to undesirable behaviors and outcomes including diminished capacity to engage in their own self-care (e.g. sleep, physical activity, etc.) build effective teacher-student relationships, implement evidence-based practices, and innovate classroom activities and lessons to meet student learning needs (Hwang et al., 2017; Larson et al., 2018; Lomas et al., 2017; Roeser et al., 2012; Schussler et al., 2018).

Table 1 provides a list of the core barriers and facilitators identified from the themes gathered from the surveys and interviews of researchers and educators. Table 2 further elaborates on the intervention mapping approach by taking the information gathered from Table 1 and applying the $\mathrm{BCW}$ to classify it in terms of needs, capabilities, opportunities, and motivations relevant to the specified target behavior. Information not directly related to the target behavior is still relevant to other aspects of the MBI (e.g., delivery, content, partnerships).

Based on the initial work, the MBI's focus on stress and emotional regulation for teachers is the most promising target behaviors to be applied in daily classroom interactions with students, as well as outside the classroom with colleagues and parents. The application of the BCW helps to ensure that researchers do not skip over this critical first step of framing the problem in behavioral terms and then identifying the target behavior(s) most likely to impact the desired outcome.

Step 4 Using the BCW analysis, we identified teacher needs as well as several barriers that could be addressed to facilitate the end goal of improving teachers' stress and emotional regulation behaviors and could be described using the BCW (see Table 2). We learned that teachers lacked knowledge and skills (capabilities) regarding stress management and emotional regulation (Greenberg et al., 2016; Travers, 2017). Additionally, the unavailability of onsite or flexible (e.g. online) professional development, lack of time, and social isolation (opportunities) served as barriers. Teachers' beliefs about their lack of control over curricular and work site decisions, growing class sizes and increased workloads also played an important role in impacting their stress and emotional regulation behaviors (motivations). Our team considered mindfulness as a potential means to help teachers regulate stress and emotions based on what was known from the literature. We considered online learning paired with on-site in-person meetings during teachers' workday as an appropriate way to address the identified needs and barriers. These on-site meetings can provide opportunities for continued skill development, reflection, and support.

Using the TDF we can further describe teachers' capability, opportunity and motivational needs (see Table 3). Teachers' physical capability related needs, included training to

Table 1 Barriers and facilitators to MBI participation

\begin{tabular}{ll}
\hline Barriers & Facilitators \\
\hline - Lack of flexible or on-site professional development & - Support of school administration \\
- Lack of time during the duty day & - Use of evidence-informed approaches \\
- Social isolation from other teaching colleagues & - Teacher learning communities \\
- Lack of control over work environment & - Alignment with state standards and accreditation \\
- Volume of work stressors in the classroom & - Mindfulness training that includes modeling and coaching \\
- Lack of training & - Collaboration with and support from others (e.g., parents, community, \\
- Lack of mindfulness content that addresses trauma, diversity, inclu- & district) \\
sion, and equity & \\
\hline
\end{tabular}


Table 2 Mapping needs and barriers to BCW COM components

\begin{tabular}{|c|c|c|}
\hline \multirow{2}{*}{$\begin{array}{l}\text { Needs and barriers (Step } 4 \text { ) } \\
\text { Need: Ability to perform activities to manage stress and regu- } \\
\text { late emotions (including self-care) }\end{array}$} & \multicolumn{2}{|c|}{ Behavioral analysis using the BCW COM components (Step 4) } \\
\hline & Capability & $\begin{array}{l}\text { Physical } \\
\text { Develop capability to perform mindfulness practices }\end{array}$ \\
\hline $\begin{array}{l}\text { Need: Ability to perform activities to manage stress and regu- } \\
\text { late emotions (including self-care) }\end{array}$ & & $\begin{array}{l}\text { Psychological } \\
\text { Develop the abilities to pay attention to present moment, monitor } \\
\text { emotions }\end{array}$ \\
\hline $\begin{array}{l}\text { Need: Ability to recognize emotions, emotional reactivity and } \\
\text { impacts }\end{array}$ & & $\begin{array}{l}\text { Psychological } \\
\text { Understand emotions, emotional response, impacts of emotions } \\
\text { on teaching }\end{array}$ \\
\hline $\begin{array}{l}\text { Need: Ability to recognize emotions, emotional reactivity and } \\
\text { impacts }\end{array}$ & & $\begin{array}{l}\text { Psychological } \\
\text { Recognize physical, emotional, and cognitive aspects of emo- } \\
\text { tional responses }\end{array}$ \\
\hline $\begin{array}{l}\text { Barriers: Lack of flexible or on-site professional development; } \\
\text { time }\end{array}$ & Opportunity & $\begin{array}{l}\text { Physical } \\
\text { Protected time and designated space within duty day }\end{array}$ \\
\hline Barrier: Social isolation & & $\begin{array}{l}\text { Social } \\
\text { Support group (cohort) and mindfulness coach }\end{array}$ \\
\hline Barriers: Beliefs about lack of control; work stressors & Motivation & $\begin{array}{l}\text { Reflective } \\
\text { Reflect on mindfulness and behavior regulation practices impact } \\
\text { on teaching behaviors }\end{array}$ \\
\hline $\begin{array}{l}\text { Barrier: Beliefs about lack of control; work stressors; social } \\
\text { isolation }\end{array}$ & & $\begin{array}{l}\text { Reflective } \\
\text { Set goals for personal practices and classroom applications }\end{array}$ \\
\hline $\begin{array}{l}\text { Barrier: Beliefs about lack of control; work stressors; social } \\
\text { isolation }\end{array}$ & & $\begin{array}{l}\text { Automatic } \\
\text { Facilitate dialogue on noticing patterns }\end{array}$ \\
\hline
\end{tabular}

address their physical skills related to specific mindfulness practices to develop their ability to recognize and regulate their emotional and stress reactions. For example, to develop the ability to moderate the stress reaction, teachers needed to be able to perform guided and unguided mindfulness practices.

Teachers' psychological capability needs included knowledge about emotions, emotional reactivity, stress, their impacts on wellbeing and classroom behaviors. Teachers needed to develop their cognitive, interpersonal and behavioral regulation skills, and memory and attention decision processes. This includes development of the awareness of self, impacts of reactions on others and self-monitoring as well as increasing attentional capacity and focus and choosing from an array of options.

Teachers also require both physical and social opportunities that include paying attention to time and meeting spaces within their duty day and ensuring learning materials could be accessed outside of work. There is also a need for individual and group social supports such as opportunities to dialogue, practice and learn from peers. From our earlier discussions, teachers reported that teaching can be isolating and that without a group of peers, continued engagement would be difficult to sustain.

Teachers' motivational needs include reframing beliefs about work related barriers such as a lack of control over decisions related to class sizes and time and the need for professional development activities to address work stress. Teachers need to reframe beliefs regarding their self-efficacy in managing stress and regulating their emotions, including time to reflect on the application and impacts of stress management and emotional regulation practices.

Steps 5-8 The next phase of our intervention design entailed selecting effective and practical strategies and modes of delivery for the MBI integrating the APEASE criteria: affordability, practicality, effectiveness/cost-effectiveness, acceptability, side effects/safety and equity. Using the BCW intervention functions and BCTs, we can describe how our MBI was designed to meet the teachers' capability, opportunity, and motivational needs described above and in Table 4. The intervention functions of modelling and training address the physical skills needed for mindfulness practice such as how to perform sitting and walking meditations. Training develops teachers' psychological capability to recognize the physical and cognitive aspects of emotions and present moment awareness by providing them instructions combined with opportunities to practice these skills. Education and training deepen teachers' understanding of intervention content (including application to their classroom practices and roles). 
Table 3 Mapping needs and barriers to TDF domains

How do you meet teachers' needs?

\begin{tabular}{|c|c|c|}
\hline \multirow{2}{*}{$\begin{array}{l}\text { Needs and barriers (Step } 4) \\
\text { Need: Ability to perform activities to manage stress and regu- } \\
\text { late emotions (including self-care) }\end{array}$} & \multicolumn{2}{|c|}{ TDF domains (Step 4a) } \\
\hline & Capability & $\begin{array}{l}\text { Physical skills } \\
\text { Sitting practice, walking practice, breath awareness }\end{array}$ \\
\hline $\begin{array}{l}\text { Need: Ability to perform activities to manage stress and regu- } \\
\text { late emotions (including self-care) }\end{array}$ & & $\begin{array}{l}\text { Cognitive and interpersonal skills; memory, attention, and deci- } \\
\text { sion processes } \\
\text { Increase attention capacity and focus; develop awareness to } \\
\text { choose responses }\end{array}$ \\
\hline $\begin{array}{l}\text { Need: Ability to recognize emotions, emotional reactivity and } \\
\text { impacts }\end{array}$ & & $\begin{array}{l}\text { Knowledge } \\
\text { Emotions, reactions and responses, physiology of stress and } \\
\text { effects on emotions, impacts on teaching }\end{array}$ \\
\hline $\begin{array}{l}\text { Need: Ability to recognize emotions, emotional reactivity and } \\
\text { impacts }\end{array}$ & & $\begin{array}{l}\text { Cognitive and interpersonal skills; behavioral regulation } \\
\text { Awareness of self, impacts of reactions on others, self-monitor- } \\
\text { ing }\end{array}$ \\
\hline $\begin{array}{l}\text { Barriers: Lack of flexible or on-site professional development; } \\
\text { time }\end{array}$ & Opportunity & $\begin{array}{l}\text { Environmental context and resources } \\
\text { Space and time to meet; availability of learning resources }\end{array}$ \\
\hline Barrier: Social isolation & & $\begin{array}{l}\text { Social influences } \\
\text { Opportunity for teachers to observe and dialogue with other } \\
\text { teachers practicing and applying concepts to teaching }\end{array}$ \\
\hline Barriers: Beliefs about lack of control; work stressors & Motivation & $\begin{array}{l}\text { Professional/social role and identity; beliefs about capabilities; } \\
\text { beliefs about consequences } \\
\text { Create beliefs and agency regarding ability to choose actions and } \\
\text { effectively regulate emotions within the classroom; provide } \\
\text { opportunities to reflect on practices and applications }\end{array}$ \\
\hline $\begin{array}{l}\text { Barrier: Beliefs about lack of control; work stressors; social } \\
\text { isolation }\end{array}$ & & $\begin{array}{l}\text { Intentions; goals } \\
\text { Provide opportunities and accountability to apply practices, } \\
\text { develop a personal practice }\end{array}$ \\
\hline $\begin{array}{l}\text { Barrier: Beliefs about lack of control; work stressors; social } \\
\text { isolation }\end{array}$ & & $\begin{array}{l}\text { Reinforcement; emotion } \\
\text { Create social supports and opportunities for reflection and shar- } \\
\text { ing of practices }\end{array}$ \\
\hline
\end{tabular}

Enablement, and environmental restructuring can facilitate engagement in the program, by removing barriers to participation through scheduling and conducting sessions onsite and during teachers' work hours. Training, enablement, persuasion, and incentivization in the intervention's group interactions and coaching provides teachers the opportunities to dialogue, practice behaviors, and to offer and receive feedback and support.

Education and persuasion, through the use of credible information (e.g., informed by research evidence), help teachers understand the impacts of stress and importance of emotional regulation in the classroom and their own personal wellbeing. Education is employed through the use of prompts and cues to foster reflection on how the intervention concepts applied to their teaching practices and their roles as educators. Enablement, persuasion, and incentivization address teacher motivational needs through dialogue, planning, goal setting and peer feedback. These provide additional emotional support, encouragement, and accountability for teachers as they developed the physical and psychological skills in the intervention.
We determined that a hybrid model of asynchronous online instruction paired with on-site group and individual support was the best approach to address the behavioral targets and barriers our team identified in Steps 1-4. The hybrid model also was best suited to deliver the intervention content based on the intervention functions and BCTs determined in Steps 5-7. Within the intervention design, the online mode of delivery addresses physical (skills) and psychological (knowledge, cognitive and interpersonal skills) capability development and prompts to address reflective motivation (beliefs about capabilities and consequences, professional role). The face-to-face mode of delivery reinforces these needs and addresses additional areas such as physical and social opportunity and automatic motivation. Table 5 illustrates the different intervention functions and BCTs addressed in the online and in person modes of delivery of the MBI.

We selected a two-course commercial online program for the asynchronous online content to introduce the physical and psychological skills needed to regulate stress and emotions and to provide opportunities for reflection. These 
Table 4 Mapping needs and barriers to TDF domains, intervention functions and BCTs

\begin{tabular}{lll}
\hline What do teachers need? & How do you meet teachers' needs? \\
\hline Needs and barriers (Step 4) & TDF domains (Step 4a) & $\begin{array}{l}\text { Intervention functions and behavior change } \\
\text { techniques (Steps } 5 \text { and } 7)\end{array}$
\end{tabular}

Need: Ability to perform activities to manage stress and regulate emotions (including self-care)

Need: Ability to perform activities to manage stress and regulate emotions (including self-care)

Need: Ability to recognize emotions, emotional reactivity and impacts

Need: Ability to recognize emotions, emotional reactivity and impacts

Barriers: Lack of flexible or on-site professional development; time

\section{Barrier: Social isolation}

Barriers: Beliefs about lack of control; work stressors

Barrier: Beliefs about lack of control; work stressors; social isolation

Barrier: Beliefs about lack of control; work stressors; social isolation
Physical skills

Sitting practice, walking practice, breath awareness

Cognitive and interpersonal skills; memory, attention, and decision processes

Increase attention capacity and focus; develop awareness to choose responses

Knowledge

Emotions, reactions and responses, physiology of stress and effects on emotions, impacts on teaching

Cognitive and interpersonal skills; behavioral regulation

Awareness of self, impacts of reactions on others, self-monitoring

Environmental context and resources Space and time to meet; availability of learning resources

Social influences

Opportunity for teachers to observe and dialogue with other teachers practicing and applying concepts to teaching

Professional/social role and identity; beliefs about capabilities; beliefs about consequences

Create beliefs and agency regarding ability to choose actions and effectively regulate emotions within the classroom; provide opportunities to reflect on practices and applications

Intentions; goals

Provide opportunities and accountability to apply practices, develop a personal practice

Reinforcement; emotion

Create social supports and opportunities for reflection and sharing of practices
Training

Demonstration of a behavior; instruction on how to perform a behavior

Modelling

Demonstration of a behavior

Training

Self-monitoring of behavior; instruction in how to perform a behavior; behavioral practice/ rehearsal

Enablement

Self-monitoring of behavior

Education

Information about social and environmental consequences; information about health consequences

Persuasion

Credible source; information about social and environmental consequences

\section{Training}

Self-monitoring of behavior; behavioral practice/rehearsal

Enablement

Self-monitoring of behavior

Environmental restructuring

Restructuring the social environment

Enablement

Social support (practical)

Training

Self-monitoring of behavior; behavioral practice/rehearsal

Enablement

Social support (emotional), Restructuring the social environment

Persuasion

Feedback on behavior, feedback on outcomes of behavior

Incentivization

Feedback on behavior, feedback on outcomes of behavior, commitment

Education

Prompts/cues

Persuasion

Identification of self as role model, feedback on behavior

Incentivization

Feedback on behavior, commitment

Enablement

Social support, action planning

Enablement

Goal setting (behavior), goal setting (outcome)

\section{Incentivization}

Commitment, incentive

Enablement

Social support, review of behavior goal(s), review of outcome goal(s) 
Table 5 Intervention functions and BCTs in online and face-to-face components

Online BCTs

Face-to-face (community of practice, coaching) BCTs

\section{Training}

- Demonstration of a behavior

- Instruction on how to perform a behavior

- Self-monitoring of behavior

- Instruction in how to perform a behavior

- Behavioral practice/rehearsal

Education

- Information about social and environmental consequences

- Information about health consequences

- Prompts/cues

Modelling

- Demonstration of a behavior

Persuasion

- Credible source

- Information about social and environmental consequences

\section{Training}

- Demonstration of a behavior

- Instruction on how to perform a behavior

- Self-monitoring of behavior

- Instruction in how to perform a behavior

- Behavioral practice/rehearsal

Education

- Information about social and environmental consequences

- Information about health consequences

- Prompts/cues

Modelling

- Demonstration of a behavior

Persuasion

- Credible source

- Information about social and environmental consequences

- Feedback on behavior

- Feedback on outcomes of behavior

- Identification of self as role model

Enablement

- Self-monitoring of behavior

- Social support (practical)

- Social support (emotional)

- Restructuring the social environment

- Action planning

- Goal setting (behavior)

- Goals setting (outcome)

- Review of behavior goal(s)

Environmental restructuring

- Restructuring the social environment

Incentivization

- Feedback on behavior

- Feedback on outcomes of behavior

- Commitment

- Incentive courses focused on personal mindfulness practice development and teaching mindfulness to children (Mindful Schools" "Mindful Educator Essentials" (n.d.-a); Mindful Schools" "Mindfulness Fundamentals" (n.d.-b)). Teachers were required to complete two six-week units of online content at their own pace including meditation practice, online reflection prompts, and content presentations. Each online unit required 30-60 min of time to complete, amounting to a total of between 6 and $12 \mathrm{~h}$ of online engagement over the two courses.

Online learning was supplemented by an additional $13 \mathrm{~h}$ of on-site, in person programming. This consisted of community of practice $(\mathrm{CP})$ meetings $(10 \times 60 \mathrm{~min})$, and individualized, one-on-one coaching sessions $(10 \times 20 \mathrm{~min})$ facilitated by a university mindfulness teacher and an onsite mindfulness teacher coach. From a behavioral perspective, these supplementary approaches are considered essential to more completely addressing teachers' mindfulness, cognitive, interpersonal and behavioral regulation skill development needs in a manner that could not be achieved solely in an online course. Importantly, they also addressed critical opportunity (e.g. protected time, social support) and motivational (e.g. reflection, practice, goal setting) needs essential for engaging in emotional regulation and mindfulness behaviors.

These program modes of delivery can be considered in light of the BCW's APEASE criteria: affordability, practicality, effectiveness/cost-effectiveness, acceptability, side effects/safety and equity (Table 6). Since lean budgets are a common feature in schools, and the project itself had fiscal constraints, affordability is one of the most important considerations. Using an existing commercially available online mindfulness course is a lower cost solution (compared to building a curriculum) to educate teachers' and address their foundational knowledge and skill needs. Additionally, a commercially available program with a history of graduates has greater appeal (acceptability) to teachers. Further, it can be considered a practical and acceptable option because 
Table 6 Mode of delivery APEASE considerations

\begin{tabular}{lll}
\hline APEASE criteria & Online courses & $\begin{array}{l}\text { In-person } \\
\text { (CPs, 1:1 } \\
\text { coaching })\end{array}$ \\
\hline Affordable & + & \\
Practical & + & \\
Effective & & + \\
Acceptable & + & + \\
Safety & & + \\
Equity & & + \\
\hline
\end{tabular}

of its asynchronous content delivery which can provide teachers a practical and flexible means to learn mindfulness content.

Situating the in-person $\mathrm{CP}$ and one-on-one sessions at school sites, during teachers' workday and utilizing coaches from the schools serves a practical purpose as it removes logistical barriers to participation. These formats are also considered effective and acceptable within professional learning communities and peer coaching initiatives. (Darling-Hammond et al., 2017). To address the practical concern of teachers' schedules and to facilitate engagement, these in-person sessions were offered at pre-arranged times within the workdays and teachers were given release time from other meetings. CP meetings and coaching sessions reinforced and expanded upon the online courses and provided time and opportunities for effective teacher professional development and included active learning, reflection and application of the content to teachers' specific classroom contexts, peer collaboration, modeling of practices, and peer and teacher/coach feedback (Archibald et al., 2011; DarlingHammond et al., 2017; DeMonte, 2013; Yoon et al., 2007).

Mindfulness can be associated with undesirable side effects, which can be even more problematic for individuals who have underlying mental health issues or have a history of trauma (Dobkin et al., 2012; Lustyk et al., 2009). Further, discussing stress and behaviors, which is a feature of mindfulness programs, can place individuals in an emotionally vulnerable position. To address the participants' safety, we included training in maintaining group norms around confidentiality and sharing. We also provided trauma training for coaches and integrated content about trauma and mindfulness into the $\mathrm{CP}$ and coaching curricula.

Our team considered equity in two parts: access and content. The intervention was designed to be a free program available to all classroom teachers. Choosing teacher emotional regulation as the focus of intervention potentially addresses educational disparities by equipping teachers to better connect with their students and attend to their educational needs (Flook et al., 2013; Harris et al., 2016; Roeser et al., 2012; Schussler et al., 2018; Soloway, 2016).
Culturally responsive content was absent from the commercial curriculum selected for the intervention and was supplemented within the in-person components. Culturally responsive content addresses educational disparities by equipping teachers with materials to create more inclusive and equitable classrooms (Gay, 2013; Howard, 2019; Ladson-Billings, 2014).

\section{Discussion}

This article illustrates how an established behavioral model, the $\mathrm{BCW}$, may be used to describe intervention mapping and the systematic development of an MBI to address teachers' stress and emotional regulation. (Michie et al., 2014, p. 59). Addressing teachers' ability to better navigate stress and emotional responses has the potential to improve classroom behaviors and wellbeing outcomes for educators that may impact student learning. The BCW's systematic design process allows researchers to select intervention components and techniques targeted to behavioral outcomes and most likely to bring about the desired change.

Our intervention design was informed by an initial exploration of current MBIs for teachers, an examination of the relevant literature, and gathering of teacher perceptions regarding their professional development needs. We learned from the educators that teachers wanted strategies to address stress management and emotional regulation, flexible or on-site professional learning, and peer support. We also learned that teachers faced significant barriers such as time constraints, increased workload, and feelings of lack of control over school decisions (Table 1). Results from this exploration revealed that no current mindfulness programs to our knowledge, offered ways to support teachers in dealing with these barriers.

From the information gathered in our initial design phase, our team set out to enhance teacher emotional regulation and wellbeing behaviors through a hybrid intervention design that incorporated online learning, group instruction, and individualized coaching. In applying the $\mathrm{BCW}$ post hoc to the MBI, we can articulate the physical and psychological capabilities, environmental resources and contexts, and motivational components needed for teachers to develop improved emotional regulation as well as delivery strategies. This additional clarity allows for further future refinement of the materials and a systematic process for the development of future MBIs.

\section{Strengths}

As of the writing of this paper, we do not know of another MBI utilizing the BCW for teacher professional development or other reasons. The BCW model provides a holistic 
approach to designing interventions which considers individuals' capabilities, logistical barriers and facilitators, and psychological motivations. In this work, the application of the BCW COM components, with the TDF demonstrate an evidence-based and coherent approach to MBI design, which can facilitate the choice of intervention activities to address teachers' needs. This systematic and transparent reporting of the intervention design process can provide an example for others interested in developing and studying complex interventions like MBIs with improved rigor and potential for replicability. (Michie et al., 2014).

\section{Limitations}

This article describes a post hoc application of the BCW to the design of an MBI that was part of a larger demonstration project in which a less structured intervention mapping process was used. Ideally, the $\mathrm{BCW}$ would be applied as part of the initial MBI design, however, there is still value in applying it post hoc to identify areas for future refinements and existing gaps. As discussed in this paper, organizing the intervention mapping process using an established model like the BCW, can also ensure a more detailed reporting of the MBI and help address issues of reproducibility.

Regarding the intervention's content, the commercial curriculum we selected for the online component of the intervention largely ignored issues of educational equity and culturally responsive practices. Discussion prompts and learning activities were added to the $\mathrm{CP}$ meetings to create links between the mindfulness content in the online courses and culturally responsive practices and trauma. While we selected a commercial program for affordability and practicality, we understood that a trade-off was made in utilizing online content that did not address these two issues.

Though widely used in healthcare and public health research and interventions (Hagger et al., 2020), the behavior change approach may be difficult for teachers, teacher educators, and researchers given the history and scholarly criticism of behaviorist approaches in education. The MBI described in this paper targets emotional and stress regulation behaviors which are well recognized goals for teachers in the field and consistent with other professional development practices such as peer learning, modeling of practices, peer and coach feedback, and application of content to teachers' specific classroom contexts (Archibald et al., 2011; Darling-Hammond et al., 2017; DeMonte, 2013; Yoon et al., 2007). We suggest that by entertaining behavioral models that demonstrate advantages in the other fields, education could similarly benefit.

Despite the comprehensiveness and rigor of the $\mathrm{BCW}$ model, applying it does have limitations. Synthesizing differing behavior change theories, the $\mathrm{BCW}$ is a complex model that reflects the complexities of human behavior.
Researchers have found the model applicable across many fields; however, the BCW lacks specific guidance as to context and population specific components required for an intervention (Howlett et al., 2019; Jatau et al., 2019; Walton et al., 2020). The model requires researchers to have a level of fluency in its application to designing interventions, and nuanced understanding of the context in which they will implement the intervention in order to determine which aspects are most applicable (Michie et al., 2014, p. $110)$. While promising in its comprehensiveness, behavior change interventions are an emerging science and the BCW model will likely be refined over time as more studies emerge (Barker et al., 2016; Ojo et al., 2019). Lastly, this paper describes the process by which we created the intervention through the lens of the $\mathrm{BCW}$ and does not address its feasibility and effectiveness; this will be addressed in subsequent papers.

\section{Comparisons to Other Research}

There is increased interest in mindfulness and MBIs to address stress and anxiety in the workplace (Bartlett et al., 2019; Janssen et al., 2018; Lomas et al., 2019) across professions (Chin et al., 2019; Donaldson-Feilder et al., 2019; Kriakous et al., 2021; Suleiman-Martos et al., 2020; Trombka et al., 2021) and globally (Charoensukmongkol, 2016; Charoensukmongkol \& Puyod, 2020; Charoensukmongkol \& Suthatorn, 2018). Similarly, MBIs are becoming increasingly popular in educational settings; however, the research on MBIs in education, similar to the greater MBI field, provide little in the way of descriptions of the actual intervention design, development, and application of theorybased intervention design strategies. Studies may detail the number of sessions, duration, and activities but descriptions around the proposed mechanisms of action in the intervention or decisions around how the program was delivered are not typically addressed (e.g., Flook et al., 2013; Jennings et al., 2011; Jennings et al., 2013; Jennings et al., 2017). One notable exception is Jennings et al., 2013, where the authors state their intervention design by mentioning its foundations in adult learning (pp. 378-9); however, the descriptions of the practices focus solely upon delivery components (e.g., didactic, experiential).

Our review of currently available programs and the literature yielded that most mindfulness in education programs are directed at teaching mindfulness skills to students versus teachers (Meiklejohn et al., 2012). Additionally, while some commercial programs focus on the development of teacher skills, research in this area is still developing (Roeser, 2014) and research focusing on intervention design (as well as effectiveness measures) is still very much needed (Hwang et al., 2017; Klingbeil et al., 2017). 


\section{Conclusions and Future Research}

This article describes the post hoc application of the $\mathrm{BCW}$ to describe the systematic intervention mapping and design of an MBI for teachers preceding a larger demonstration project. The description of this process demonstrates how we gathered relevant information from the research literature and stakeholders in the field. From this initial exploration, we subsequently applied the steps in the $\mathrm{BCW}$ to articulate the issues considered in the MBI mapping and design process including identifying the problem, describing it in behavioral terms, determining intervention functions, and then selecting behavior change techniques and modes of delivery. Through the use of a rigorous, theory-based approach and detailed reporting, it is hoped that this paper can serve as a model for future researchers developing MBIs for teachers.

The comprehensive structure of the $\mathrm{BCW}$ allowed us to dissect the intervention and intervention design process. The BCW also enabled us to re-examine the issue of teacher stress and emotional regulation through a behavioral lens and then systematically work through the intervention design from identifying behaviors and needs to selecting the most effective strategies and modes of delivery. The systematic approach of the BCW allows for a more targeted and complete intervention to target the desired behavior change, enhanced emotional and stress regulation in teachers. Illustrated from this perspective, it allows intervention designers and researchers the ability to make decisions about which techniques and delivery components to include in their interventions, systematically moving from identifying the desired behavior to the means most likely to bring about the intended change. Given the breadth of approaches in teacher professional development, extant literature supporting the potential use of mindfulness to improve emotional wellbeing, recommendations in the emerging literature encompassing mindfulness applications for education, and the extensive body of research utilizing this intervention design approach within health care interventions, the $\mathrm{BCW}$ shows promise for use within teacher professional development in mindfulness and emotional regulation. Applying the $\mathrm{BCW}$ to future MBIs may help future researchers design and iterate interventions with greater precision and rigor.

Current research on teachers tends to focus on MBIs to address teacher stress (e.g., Flook et al., 2013) but with little attention to classroom impacts (Lomas et al., 2017). Similar to studies on youth, interventions for educators lack reporting about fidelity and intervention components (Emerson et al., 2017; Hwang et al., 2017; Klingbeil et al., 2017; Lomas et al., 2017). Additionally, commercial programs for education have proliferated typically offering curriculum geared towards teaching children how to perform mindfulness practices (Meiklejohn et al., 2012). Training for teachers to deliver these programs varies widely ranging from multiple day residential retreats, online learning, or half-day workshops (Semenov et al., in press).

Though not specifically addressed in this paper, the variability in training is an additional intervention integrity issue that needs to be addressed by researchers and reported upon in their studies (Crane \& Hecht, 2018). Future research should consider examining approaches that address how MBIs for teachers may target specific behaviors, including how intervention components work towards building the changes educators and researchers wish to see enacted. The comprehensive structure of the $\mathrm{BCW}$ is particularly important in articulating teacher needs and barriers, especially around the issues of contractual time and physical space. While these issues are well known within the teacher education and professional development literature, they are less so in the MBI field, and are important to take into account for successful implementation in educational settings. While our discussion focused on those issues within the MBI literature related to intervention design and reporting (ex: Emerson et al., 2017; Hwang et al., 2017), taking into consideration the need for contractual time and physical space may benefit future designs and studies on MBIs for teachers. Providing rigorous detail in how these interventions are designed, delivered, and evaluated will allow future researchers to establish a robust knowledge base to affect change in this important area.

Data Availability Not applicable.

\section{Declarations}

Disclosure of Potential Conflicts of Interest Funding for the reported work which is part of a larger demonstration project was provided through philanthropic support managed by the University of Minnesota Foundation and in-kind contributions of the authors.

Research Involving Human Participants and/or Animals This work was classified as 'not human subjects research' by the University of Minnesota Internal Review Board.

Informed Consent This work was classified as 'not human subjects research' by the University of Minnesota Internal Review Board.

Open Access This article is licensed under a Creative Commons Attribution 4.0 International License, which permits use, sharing, adaptation, distribution and reproduction in any medium or format, as long as you give appropriate credit to the original author(s) and the source, provide a link to the Creative Commons licence, and indicate if changes were made. The images or other third party material in this article are included in the article's Creative Commons licence, unless indicated otherwise in a credit line to the material. If material is not included in the article's Creative Commons licence and your intended use is not 
permitted by statutory regulation or exceeds the permitted use, you will need to obtain permission directly from the copyright holder. To view a copy of this licence, visit http://creativecommons.org/licenses/by/4.0/.

\section{References}

Archibald, S., Coggshall, J. G., Croft, A., \& Goe, L. (2011). Highquality professional development for all teachers: Effectively allocating resources. National Comprehensive Center for Teacher Quality. https://files.eric.ed.gov/fulltext/ED520732.pdf

Barker, F., Atkins, L., \& de Lusignan, S. (2016). Applying the COM-B behaviour model and behaviour change wheel to develop an intervention to improve hearing-aid use in adult auditory rehabilitation. International Journal of Audiology, 55(sup3), S90-S98.

Bartlett, L., Martin, A., Neil, A. L., Memish, K., Otahal, P., Kilpatrick, M., \& Sanderson, K. (2019). A systematic review and metaanalysis of workplace mindfulness training randomized controlled trials. Journal of Occupational Health Psychology, 24(1), 108.

Bishop, S. R., Lau, M., Shapiro, S., Carlson, L., Anderson, N. D., Carmody, J., Segal, Z. V., Abbey, S., Speca, M., Velting, D., \& Devins, G. (2004). Mindfulness: A proposed operational definition. Clinical Psychology: Science and Practice, 11(3), 230-241.

Bonell, C., Michie, S., Reicher, S., West, R., Bear, L., Yardley, L., Curtis, V., Amlôt, R., \& Rubin, G. J. (2020). Harnessing behavioural science in public health campaigns to maintain 'social distancing' in response to the COVID-19 pandemic: Key principles. Journal of Epidemiology \& Community Health, 74(8), 617-619.

Cane, J., O'Connor, D., \& Michie, S. (2012). Validation of the theoretical domains framework for use in behaviour change and implementation research. Implementation Science, 7(1), 37.

Charoensukmongkol, P. (2016). The role of mindfulness in reducing English language anxiety among Thai college students. International Journal of Bilingual Education and Bilingualism, 22(4), 414-427.

Charoensukmongkol, P., \& Puyod, J. V. (2020). Mindfulness and emotional exhaustion in call center agents in the Philippines: Moderating roles of work and personal characteristics. The Journal of General Psychology, 1-25.

Charoensukmongkol, P., \& Suthatorn, P. (2018). Salespeople's trait mindfulness and emotional exhaustion: The mediating roles of optimism, resilience, and self-efficacy. International Journal of Services, Economics and Management, 9(2), 125-142.

Chin, B., Slutsky, J., Raye, J., \& Creswell, J. D. (2019). Mindfulness training reduces stress at work: A randomized controlled trial. Mindfulness, 10(4), 627-638.

Craig, P., Dieppe, P., Macintyre, S., Michie, S., Nazareth, I., \& Petticrew, M. (2013). Developing and evaluating complex interventions: The new Medical Research Council guidance. International Journal of Nursing Studies, 50(5), 587-592.

Crane, R. S., \& Hecht, F. M. (2018). Intervention integrity in mindfulness-based research. Mindfulness, 1-11.

Crane, R. S., Brewer, J., Feldman, C., Kabat-Zinn, J., Santorelli, S., Williams, J. M. G., \& Kuyken, W. (2017). What defines mindfulness-based programs? The warp and the weft. Psychological Medicine, 47(6), 990-999.

Creswell, J. D. (2017). Mindfulness interventions. Annual Review of Psychology, 68, 491-516.

Darling-Hammond, L., Hyler, M. E., \& Gardner, M. (2017). Effective teacher professional development. Learning Policy Institute. https://learningpolicyinstitute.org/sites/default/files/product-files/ Effective_Teacher_Professional_Development_REPORT.pdf

Dawn, S., Talukdar, P., Bhattacharjee, S., \& Singh, O. P. (2016). A study on job related stress among school teachers in different schools of West Bengal, India. Eastern Journal of Psychiatry, 19(1), 12-17.

DeMonte, J. (2013). High-quality professional development for teachers: Supporting teacher training to improve student learning. Center for American Progress. https://files.eric.ed.gov/fulltext/ ED561095.pdf

Dobkin, P. L., Irving, J. A., \& Amar, S. (2012). For whom may participation in a mindfulness-based stress reduction program be contraindicated? Mindfulness, 3, 44-50.

Donaldson-Feilder, E., Lewis, R., \& Yarker, J. (2019). What outcomes have mindfulness and meditation interventions for managers and leaders achieved? A systematic review. European Journal of Work and Organizational Psychology, 28(1), 11-29.

Eisele, A., Schagg, D., \& Göhner, W. (2020). Exercise promotion in physiotherapy: A qualitative study providing insights into German physiotherapists' practices and experiences. Musculoskeletal Science Practitioner, 45, 102104.

Emerson, L., Leyland, A., Hudson, K., Rowse, G., Hanley, P., \& HughJones, S. (2017). Teaching mindfulness to teachers: A systematic review and narrative synthesis. Mindfulness, 8, 1136-1149.

Espelage, D., Anderman, E. M., Brown, V. E., Jones, A., Lane, K. L., McMahon, S. D., Reddy, L. A., \& Reynolds, C. R. (2013). Understanding and preventing violence directed against teachers: Recommendations for a national research, practice, and policy agenda. American Psychologist, 68(2), 75.

Flook, L., Goldberg, S. B., Pinger, L., Bonus, K., \& Davidson, R. J. (2013). Mindfulness for teachers: A pilot study to assess effects on stress, burnout, and teaching efficacy. Mind, Brain, and Education, 7(3), 182-195.

Gallup. (2014). State of America's schools report. Washington.

Garrick, A., Winwood, P. C., Mak, A. S., Cathcart, S., Bakker, A. B., \& Lushington, K. (2014). Prevalence and organizational factors of psychological injury among Australian school teachers. Australian Journal of Organizational Psychology., 7, 1-12.

Gay, G. (2013). Teaching to and through cultural diversity. Curriculum Inquiry, 43(1), 48-70.

Gotink, R. A., Chu, P., Busschbach, J. J., Benson, H., Fricchione, G. L., \& Hunink, M. M. (2015). Standardised mindfulness-based interventions in healthcare: An overview of systematic reviews and meta-analyses of RCTs. PLoS One, 10(4), e0124344.

Goyal, M., Singh, S., Sibinga, E. M., Gould, N. F., Rowland-Seymour, A., Sharma, R., Berger, Z., Sleicher, D., Maron, D. D., Shihab, H. M., \& Ranasinghe, P. D. (2014). Meditation programs for psychological stress and well-being: A systematic review and metaanalysis. JAMA Internal Medicine, 174(3), 357-368.

Greenberg, M. T., Brown, J. L., \& Abenavoli, R. M. (2016). Teacher stress and health effects on teachers, students, and schools. Pennsylvania State University.

Hagger, M., Cameron, L., Hamilton, K., Hankonen, N., \& Lintunen, T. (2020). Changing behavior: A theory- and evidence-based approach. In M. Hagger, L. Cameron, K. Hamilton, N. Hankonen, \& T. Lintunen (Eds.), The handbook of behavior change (pp. 1-14). Cambridge University Press.

Harris, A. R., Jennings, P. A., Katz, D. A., Abenavoli, R. M., \& Greenberg, M. T. (2016). Promoting stress management and wellbeing in educators: Feasibility and efficacy of a school-based yoga and mindfulness intervention. Mindfulness, 7(1), 143-154.

Haynes, M., Maddock, A., \& Goldrick, L. (2014). On the path to equity: Improving the effectiveness of beginning teachers. Alliance for Excellent Education. https://mk0all4edorgjxiy8xf9.kinstacdn. com/wp-content/uploads/2014/07/PathToEquity.pdf

Hecker, T., Goessmann, K., Nkuba, M., \& Hermenau, K. (2018). Teacher stress intensifies violent disciplining in Tanzanian secondary schools. Child Abuse \& Neglect, 76, 173-183.

Herman, K. C., Hickmon-Rosa, J. E., \& Reinke, W. M. (2018). Empirically derived profiles of teacher stress, burnout, self-efficacy, and 
coping and associated student outcomes. Journal of Positive Behavior Interventions, 20(2), 90-100.

Howard, T. C. (2019). Why race and culture matter in schools: Closing the achievement gap in America's classrooms. Teachers College Press.

Howlett, N., Schulz, J., Trivedi, D., Troop, N., \& Chater, A. (2019). A prospective study exploring the construct and predictive validity of the COM-B model for physical activity. Journal of Health Psychology, 24(10), 1378-1391.

Hurley, D. A., Murphy, L. C., Hayes, D., Hall, A. M., Toomey, E., McDonough, S. M., Lonsdale, C., Walsh, N. E., Guerin, S., \& Matthews, J. (2015). Using intervention mapping to develop a theory-driven, group-based complex intervention to support selfmanagement of osteoarthritis and low back pain (SOLAS). Implementation Science, 11(1), 56.

Hwang, Y. S., Bartlett, B., Greben, M., \& Hand, K. (2017). A systematic review of mindfulness interventions for in-service teachers: A tool to enhance teacher wellbeing and performance. Teaching and Teacher Education, 64, 26-42.

Ingersol, R. M., Merrill, E., Stuckey, D., \& Collins, G. (2018). Seven trends: The transformation of the teaching force. Updated October 2018. CPRE research report \#RR 2018-2. Consortium for Policy Research in Education.

Janssen, M., Heerkens, Y., Kuijer, W., Van Der Heijden, B., \& Engels, J. (2018). Effects of mindfulness-based stress reduction on employees' mental health: A systematic review. PLoS One, 13(1), e0191332.

Jatau, A. I., Peterson, G. M., Bereznicki, L., Dwan, C., Black, J. A., Bezabhe, W. M., \& Wimmer, B. C. (2019). Applying the capability, opportunity, and motivation behaviour model (COM-B) to guide the development of interventions to improve early detection of atrial fibrillation. Clinical Medicine Insights: Cardiology, 13, 1179546819885134

Jennings, P. A., \& Greenberg, M. T. (2009). The prosocial classroom: Teacher social and emotional competence in relation to student and classroom outcomes. Review of Educational Research, 79(1), 491-525.

Jennings, P. A., Snowberg, K. E., Coccia, M. A., \& Greenberg, M. T. (2011). Improving classroom learning environments by cultivating awareness and resilience in education (CARE): Results of two pilot studies. The Journal of Classroom Interaction, 37-48.

Jennings, P. A., Frank, J. L., Snowberg, K. E., Coccia, M. A., \& Greenberg, M. T. (2013). Improving classroom learning environments by cultivating awareness and resilience in education (CARE): Results of a randomized controlled trial. School Psychology Quarterly, 28(4), 374.

Jennings, P. A., Brown, J. L., Frank, J. L., Doyle, S., Oh, Y., Davis, R., Rasheed, D., DeWeese, A., DeMauro, A. A., Cham, H., \& Greenberg, M. T. (2017). Impacts of the CARE for Teachers program on teachers' social and emotional competence and classroom interactions. Journal of Educational Psychology, 109(7), 1010.

Johnson, S., Cooper, C., Cartwright, S., Donald, I., Taylor, P., \& Millet, C. (2005). The experience of work related stress across occupations. Journal of Managerial Psychology, 20(2), 178-187.

Kena, G., Musu-Gillette, L., Robinson, J., Wang, X., Rathbun, A., Zhang, J., Wilkinson-Flicker, S., Barmer, A., \& Dunlop Velez, E. (2015). The condition of education 2015 (NCES 2015-144). : U.S. Department of Education.

Khoury, B., Sharma, M., Rush, S. E., \& Fournier, C. (2015). Mindfulness-based stress reduction for healthy individuals: A metaanalysis. Journal of Psychosomatic Research, 78(6), 519-528.

Klingbeil, D. A., \& Renshaw, T. L. (2018). Mindfulness-based interventions for teachers: A meta-analysis of the emerging evidence base. School Psychology Quarterly, 33(4), 501.
Klingbeil, D. A., Renshaw, T. L., Willenbrink, J. B., Copek, R. A., Chan, K. T., Haddock, A., Yassine, J., \& Clifton, J. (2017). Mindfulness-based interventions with youth: A comprehensive metaanalysis of group-design studies. Journal of School Psychology, $63,77-103$

Kok, G. (2018). A practical guide to effective behavior change: How to apply theory-and evidence-based behavior change methods in an intervention. European Health Psychologist, 16(5), 156-170.

Kriakous, S. A., Elliott, K. A., Lamers, C., \& Owen, R. (2021). The effectiveness of mindfulness-based stress reduction on the psychological functioning of healthcare professionals: A systematic review. Mindfulness, 12(1), 1-28.

Kyriacou, C. (2001). Teacher stress: Directions for future research. Educational Review, 53(1), 37-35.

Ladson-Billings, G. (2014). Culturally relevant pedagogy 2.0: aka the remix. Harvard Educational Review, 84(1), 74-84.

Larson, M., Cook, C. R., Fiat, A., \& Lyon, A. R. (2018). Stressed teachers don't make good implementers: Examining the interplay between stress reduction and intervention fidelity. School Mental Health, 10(1), 61-76.

Liu, S., \& Onwuegbuzie, A. J. (2012). Chinese teachers' work stress and their turnover intention. International Journal of Educational Research, 53, 160-170.

Lomas, T., Medina, J. C., Ivtzan, I., Rupprecht, S., \& Eiroa-Orosa F. J. (2017). The impact of mindfulness on the wellbeing and performance of educators: A systematic review of the empirical literature. Teaching and Teacher Education, 61, 132-141.

Lomas, T., Medina, J. C., Ivtzan, I., Rupprecht, S., \& Eiroa-Orosa, F. J. (2019). Mindfulness-based interventions in the workplace: An inclusive systematic review and meta-analysis of their impact upon wellbeing. The Journal of Positive Psychology, 14(5), 625-640.

Lustyk, M. K., Chawla, N., Nolan, R., \& Marlatt, G. A. (2009). Mindfulness meditation research: Issues of participant screening, safety procedures, and researcher training. Advances in Mind-Body Medicine, 24(1), 20-30.

McCarthy, C. J., Lineback, S., Fitchett, P. G., Lambert, R. G., Eyal, M., \& Boyle, L. H. (2017). The role of culture and other contextual factors in educator stress. In T. M. McIntrye, S. E. McIntyre, \& D. J. Francis (Eds.), Educator stress: An occupational health perspective (pp. 157-177). Springer.

Meiklejohn, J., Phillips, C., Freedman, M. L., Griffin, M. L., Biegel, G., Roach, A., Frank, J., Burke, C., Pinger, L., Soloway, G., \& Isberg, R. (2012). Integrating mindfulness training into K-12 education: Fostering the resilience of teachers and students. Mindfulness, 3(4), 291-307.

Metropolitan Life Insurance Company. (2012). The MetLife survey of the American teacher: Challenges for school leadership. ERIC Clearinghouse.

Michie, S., Atkins, L., \& West, R. (2014). The behaviour change wheel: A guide to designing interventions. Silverback Publishing.

Michie, S., West, R., Rogers, M.B., Bonell, C., Rubin, G.J., \& Amlôt, R. (2020). Reducing SARS-CoV-2 transmission in the UK: A behavioural science approach to identifying options for increasing adherence to social distancing and shielding vulnerable people. British Journal of Health Psychology, published online ahead of print, 2020 May 19.

Mindful Schools. (n.d.-a). Mindfulness Fundamentals.Retrieved April 10, 2020, from https://www.mindfulschools.org/training/mindf ulness-fundamentals/

Mindful Schools (n.d.-b). Mindful Educator Essentials. Retrieved April 10, 2020, from https://www.mindfulschools.org/training/mindfuleducator-essentials/

Minian, N., Corrin, T., Lingam, M., deRuiter, W., Rodak, T., Taylor, V., Manson, H., Dragonetti, R., Zawertailo, L., Melamed, O., Hahn, 
M., \& Selby, P. (2020). Identifying contexts and mechanisms in multiple behavior change interventions affecting smoking cessation success: A rapid realist review. BMC Public Health, 20(1), 918.

Montgomery, C., \& Rupp, A. A. (2005). A meta-analysis for exploring the diverse causes and effects of stress in teachers. Canadian Journal of Education, 28(3), 458-486.

Ojo, S. O., Bailey, D. P., Brierley, M. L., Hewson, D. J., \& Chater, A. M. (2019). Breaking barriers: Using the behavior change wheel to develop a tailored intervention to overcome workplace inhibitors to breaking up sitting time. BMC Public Health, 19(1), 1126.

Quin, D. (2017). Longitudinal and contextual associations between teacher-student relationships and student engagement: A systematic review. Review of Educational Research, 87(2), 345-387.

Roeser, R. W. (2014). The emergence of mindfulness-based interventions in educational settings. Advances in Motivation and Achievement, 18, 379-419.

Roeser, R. W., Skinner, E., Beers, J., \& Jennings, P. A. (2012). Mindfulness training and teachers' professional development: An emerging area of research and practice. Child Development Perspectives, $6(2), 167-173$

Schussler, D. L., Greenberg, M., DeWeese, A., Rasheed, D., DeMauro, A., Jennings, P. A., \& Brown, J. (2018). Stress and release: Cases studies of teacher resilience following a mindfulness-based intervention. American Journal of Education, 125(1), 1-28.

Semenov, A., Kennedy, D., \& Zelazo, P. (in press). Mindfulness and executive function: Implications for learning and early childhood education. In Educational Neuroscience: Development Across the Life Span.

Skinner, E., \& Beers, J. (2016). Mindfulness and teachers' coping in the classroom: A developmental model of teacher stress, coping, and everyday resilience. In K. A. Schonert-Reichl \& R. W. Roeser (Eds.), Handbook of mindfulness in education (pp. 99-118). Springer.

Soloway, G. B. (2016). Preparing teacher candidates for the present: Investigating the value of mindfulness-training in teacher education. In K. A. Schonert-Reichl \& R. W. Roeser (Eds.), Handbook of mindfulness in education (pp. 191-205). Springer.
Suleiman-Martos, N., Gomez-Urquiza, J. L., Aguayo-Estremera, R., Cañadas-De La Fuente, G. A., De La Fuente-Solana, E. I., \& Albendín-García, L. (2020). The effect of mindfulness training on burnout syndrome in nursing: A systematic review and metaanalysis. Journal of Advanced Nursing, 76(5), 1124-1140.

Travers, C. (2017). Current knowledge on the nature, prevalence, sources and potential impact of teacher stress. In T. M. McIntrye, S. E. McIntyre, \& D. J. Francis (Eds.), Educator stress: An occupational health perspective (pp. 23-54). Springer.

Trombka, M., Demarzo, M., Campos, D., Antonio, S. B., Cicuto, K., Walcher, A. L., García-Campayo, J., Schuman-Olivier, Z., \& Rocha, N. S. (2021). Mindfulness training improves quality of life and reduces depression and anxiety symptoms among Police officers: Results from the POLICE study-A multicenter randomized controlled trial. Frontiers in Psychiatry, 12, 112.

Walton, H., Spector, A., Roberts, A., Williamson, M., Bhatt, J., Tombor, I., \& Michie, S. (2020). Developing strategies to improve fidelity of delivery of, and engagement with, a complex intervention to improve independence in dementia: A mixed methods study. BMC Medical Research Methodology, 20(1), 1-19.

Yoon, K. S., Duncan, T., Lee, S. W., Scarloss, B., \& Shapley, K. (2007). Reviewing the evidence on how teacher professional development affects student achievement (Issues \& Answers Report, REL 2007No. 033). : U.S. Department of Education.

Zarate, K., Maggin, D. M., \& Passmore, A. (2019). Meta-analysis of mindfulness training on teacher well-being. Psychology in the Schools, 56(10), 1700-1715.

Zurlo, M. C., Pes, D., \& Capasso, R. (2013). Teacher stress questionnaire: Validity and reliability study in Italy. Psychological Reports: Measures and Statistics, 113(2), 290-517.

Publisher's Note Springer Nature remains neutral with regard to jurisdictional claims in published maps and institutional affiliations. 